\title{
Temporal lobe epilepsy: origin and significance of simple and complex auras
}

\author{
DAVID C TAYLOR, MOIRA LOCHERY \\ From the University Department of Psychiatry, Child and Adolescent Psychiatry, Manchester, UK
}

SUMMARY The aura experience of 88 patients with temporal lobe epilepsy was recorded, classified and analysed. Despite the great richness of the 215 experiences described, correlations with left or right brain, nature of lesion, age of onset, etc. were only apparent when a classification into three aura groups was used. "Simple primitive" auras as sole auras were more likely with early onset epilepsy, in lower IQ patients, in males, from the right temporal lobe, and with mesial temporal sclerosis. Exclusively "intellectual" auras were confined to a group of high IQ males. The number of aura experiences described per person correlated with Verbal IQ for males but not females, but also varied with side, sex, and nature of lesion. The results are discussed in terms of the necessary conditions for aura and their relevance and in relationship to the results of brain stimulation studies by Penfield and others.

\section{Between those happenings that prefigure it And those that happen in its anamnesis Occurs the Event, but that no human wit Can recognize until all happening ceases. ${ }^{1}$}

Aura is the brief subjective experience giving immediate precognisance of some epileptic fits. Ounsted ${ }^{2}$ realised that aura was a universal phase in paroxysmal behaviours, the immediate, specific, subjective, warning of the system going absolute. The paroxysmal behaviours all involve systems which are biologically necessary, closely related to the emotions or to affects, and not entirely under conscious control, such as sneezing, laughing, crying, raging, vomiting, defecating, urinating, labour and orgasm. Many of these behaviours become incorporated into seizures as the integrative functions of the temporal lobe, mediating between neuro-vegetative function and higher order thought, are thrown into chaos.

A 12 year old girl, verbal IQ 133, referred for stealing, wetting, soiling, failing in school, not taking her

An early draft of this paper was given at the Royal Society of Medicine on 1 December 1982. Brief summaries of attempts at analysis on the aura data are given in McLean Hospital Journal, June 1977.

Address for reprint requests: Prof D C Taylor, University Department of Psychiatry, Child and Adolescent Psychiatry, Jesson House (RMCH), Manchester Road, Swinton, Manchester M27 IFG, UK.

Received 16 August 1986 and in revised form 4 December 1986. Accepted 5 December 1986 medicines, and being unhappy and immature, described the onset of her occasional seizures. "The first thing is that everything I can hear becomes louder. Then the echoes begin. Then the dream starts in which I'm in a railway train which goes round and round in a loop faster and faster until it crashes. Then I wake up." What are the neurological and psychiatric implications of such aura experiences?

The study of aura has a respectable history since the introduction of the term by Pelops, the master of Galen, ${ }^{3}$ to describe the "breath of air" which was his patient's premonition of a seizure. Reported auras seem stable between cultures and over historical time. Bernard of Gordon's patient reported "a confusion in the head, and a darkness in the eyes" $(1542)^{4}$ and Gastaut et al (1959) " a black fog before the eyes". We owe the realisation of the existence of psychical disorder in the seizure to Griesinger $(1867)^{6}$ (or possibly to Cheyne), "Thus we may frequently observe attacks sometimes preceding and sometimes alternating with intermittent convulsions which consist principally in psychical anomaly either entirely without or with very limited, disorder of movement." $\mathrm{He}$ described mental pain, incoherence, painful dreams, "a state of dreaming". Priority for the description of the "dreamy state" is more usually, but falsely, attributed to Jackson, but Jackson did localise its origin within the temporal lobe in his patient $\mathrm{Dr} \mathrm{Z} .^{8} \mathrm{Dr} \mathrm{Zs}$ account of his own aura was "... my attention was suddenly absorbed in my own mental state of which I knew no more than it seemed to me to be a vivid and 
unexpected 'recollection'-of what, I do not know..." Such emanations provided crucial material for the contemporary development of ideas about the multi-layered structure of mind, ${ }^{9}$ the unconscious, ${ }^{10}$ and much material for psychoanalytic speculation. Who directs behaviour when the self is absent? Who reports the experience? Considering the early recognition of the potential of studying aura there is a surprising dearth of enterprising studies subsequently.

In their massive Pan American study, Lennox and Cobb $^{11}$ recognised 327 different sensations in the 1527 cases described to them by reports from many doctors. The classification of these sensations was then and has been since, idiosyncratic and unrelated to the structural lesions to which, however remotely, they seem causally connected. ${ }^{12}$ The fundamental difference, in qualitative terms and in psychological import, between formed complex experiences on the one hand and crude visceral or trifling peripheral sensations on the other, has passed largely unremarked. Aura has potential interest to classical neurology, in the location of lesions within the brain; to neurophysiology in the mechanisms concerned with the experience; to developmental medicine in differences in their expression with age of onset of epilepsy; to psychology through their association with cerebral organisation of function and their relationship to other skills; and to psychopathology in terms of their content in relation to mental state and personal experience.

The study of aura has become inextricably involved in brain stimulation experiments since the time of Penfield's ${ }^{13}$ work on his unanaesthetised patients. The results of these studies will also be discussed here.

Aura must occur when there is still functioning, remembering, brain. The report may be only a retained fragment of the whole experience. Aura would usually consist of recognisable states, states that have names, though "indescribable feelings" are reported. To be recognisably an "aura" it would need to be consistent from one fit to the next. Though auras do change over time, the change is usually a condensation from complexity. ${ }^{14}$

The basis of simple auras might only mean the energising of areas of brain responsible normally for the registration of peripheral or central vegetative events. This seems relatively simple. Four of the possible bases for complex aura are: (1) that it is experienced as an aspect of primary process thinking by a generally, but partially, impaired brain. ${ }^{15}$ Here the problem is to explain the consistency of aura. (2) Complex aura might be a specific, psychopathologically relevant, package associated with an event occurring before the onset of epilepsy. ${ }^{16}$ (3) Aura might be an experiential package, at varying degrees of complexity, released by local excitation from local storage or by evocation from facilitated pathways. ${ }^{17}$ (4) Brains that describe complex auras may be different in various ways from those that do not. That is, they may have unusual organisation as a result of compensation for some kind of injury during development. $^{18}$

This study of aura was aimed to address some of these issues through detailed analysis of a group of patients about whom a great deal was already known. ${ }^{19-23}$

\section{Method}

The group was composed of 88 patients from the series submitted to temporal lobectomy by the late Murray Falconer. It included all 47 of the then available patients with "alien tissue" (AT) in the resected lobe and this group was contrasted with 41 available patients with "mesial temporal sclerosis" (MTS) who were operated upon contemporaneously. Thus, until the pathological findings were made available there had been originally, at the time of history taking, no reason to distinguish one group from the other. The 88 patients contained 54 males and 34 females; 41 were operated on the left and 47 on the right temporal lobe. Throughout the analysis of the information derived from temporal lobectomy, the important variables have been shown to be: age at onset of epilepsy, type of pathological changes in the resected lobe, sex, side of operation, intelligence, mental state, and social performance. These were selected as the principal factors in this analysis too.

Verbal and Performance IQs refer to those Wechsler Tests which were done on the nearest date before the operation. ${ }^{24}$ Handedness was taken from the neurosurgeon's operation notes and "left-handed" refers to any patient listed as not fully right-handed.

Age at first fit coded the age in years at the time of the first epileptic seizure ever, and not the age at "established" epilepsy. The Social Score was a global assessment made on the basis described in Taylor and Falconer ${ }^{19}$ ranging from 7 for the best to 32 for the worst social adjustment. This score was made again at the follow-up assessment. Scores below 15 were regarded as "good" adjustment and above 15 was "bad". Psychotic refers to the 13 patients previously analysed $^{25}$ with chronic schizophrenia-like psychosis. Outcome in terms of seizures was rated in a manner which was not scalar but covered complete relief, current fit freedom, improvement, no improvement, worse, and relapse after improvement. Aura was amply described in the clinical notes made before the operation. The clinicians taking the detailed history over the years were psychiatrists well versed in eliciting subjective information. They were also guided by a schedule of auras about which they made specific enquiry. A progressive analysis was made by reading the data sheets and working on the premise of producing a reasonably modest number of aura categories for analysis. (The example case given above experienced macrusia, hallucination, and rotation). This first level of analysis produced a list of 21 different sorts of auras (table 1(a)). The second level of "aura" analysis is a condensation derived from the first. It reduces " $\mathrm{N}$ " variably because some individuals may have 
Table 1 Total number of aura experiences by lesion, side of operation and sex

(a) Original 21 groups, "Level l"

No Aura

Epigastric Neutral

Epigastric Fear

Nausea

Cephalic

Rectal

Penile/Vaginal

Peripheral-sensory
Taste

Smell

Micropsia

Microcusia

Rotation-vertigo
Hallucinations

Doppelganger

Intensification

Depersonalisation/Derealisation

Anaesthetic

Time Anomalies

Jamais Vu

Déja Vu

Idiosyncratic

(b) Condensation, "Level 2" (Three groups derived from columns above) Alien tissue MTS

experienced auras in two or more groups of the former category. (Table 1(b)). The three Aura groups of 1(b) are drawn from the three columns of $1(\mathrm{a})$.

However, some patients still experienced an aura (or more than one) in each of these three remaining categories. In order to produce a classification of auras from level 2 which was exclusive of overlap, seven groups were required, plus the group for people with no aura (see table 5).

The two levels of aura classification have to be treated as independent of one another, two different experiments in classification formed for the purpose of exploring the meaning of "aura". Each level of classification was guided by anatomical and neurophysiological considerations but our grasp of the cerebral basis of the ictal experience or its interpretation is tenuous. At level 2, the division is essentially into autonomic/vegetative feelings (Simple Primitive); those involving the Special Senses (Special Senses); and those which are more interpretive, experiential, poetic (Intellectual).

\section{Results}

\section{Aura description and frequency}

(1) No aura

Nine of the 88 patients reported no aura, six were males and three females. Seven were in the AT group including five in the left AT group where they form a quarter of that group $(n=20)$.

\section{(2) Level 1}

Of the 21 original categories (table 1), cephalic auras (27) were the most frequent. These are usually reported as a "funny feeling" or an "indescribable" feeling in the head which beggars further explication so it is sometimes overlooked and under-reported. Sensations in the epigastrium were equally associated (24) or unassociated (23) with "fear". The "fear" component occurred twice as often with MTS as with AT lesions but this was not statistically significant $\left(\chi^{2}\right.$ $2.55, \mathrm{p}<0.106 \mathrm{NS})$. The "idiosyncratic" group (22) was a portmanteau of unclassifiable "intellectual" auras, examples of which are listed later. Déja vu (16) was the next most commonly recorded, perhaps because it is well-known to clinicians, but micropsia (13) is far less commonly recognised but was almost as frequently noted. Nausea (12) and auras of taste (10) and smell (10) and hallucinations (10) were all relatively common.

The distribution of these 215 auras across the eight groups, composed for the purpose of detailed analysis by sex, lesion, side and any given aura, revealed no interesting associations and they are not fully tabulated. Auras arose from the right (125) slighly more than from the left (90) and from AT lesions (112) more than from MTS (103). But these contrasts can

Table 2 Mean number of auras per person

\begin{tabular}{|c|c|c|c|c|c|c|c|c|}
\hline & \multicolumn{4}{|l|}{$A T$} & \multicolumn{4}{|c|}{$M T S$} \\
\hline & $\begin{array}{l}\text { Left } \\
M\end{array}$ & $F$ & $\begin{array}{l}\text { Right } \\
M\end{array}$ & $F$ & $\begin{array}{l}\text { Left } \\
M\end{array}$ & $F$ & $\begin{array}{l}\text { Right } \\
M\end{array}$ & $F$ \\
\hline $\begin{array}{l}\text { "N" } \\
\text { Auras } \\
\text { Mean }\end{array}$ & $\begin{array}{l}10 \\
12 \\
1 \cdot 2\end{array}$ & $\begin{array}{c}10 \\
23 \\
2 \cdot 3\end{array}$ & $\begin{array}{c}18 \\
55 \\
3 \cdot 1\end{array}$ & $\begin{array}{c}9 \\
22 \\
2 \cdot 4\end{array}$ & $\begin{array}{c}16 \\
37 \\
2 \cdot 3\end{array}$ & $\begin{array}{c}5 \\
18 \\
3.6\end{array}$ & $\begin{array}{c}10 \\
18 \\
1.8\end{array}$ & $\begin{array}{c}10 \\
30 \\
3 \cdot 0\end{array}$ \\
\hline
\end{tabular}


Table 3 Mean number of auras and VIQ

\begin{tabular}{|c|c|c|}
\hline $\begin{array}{l}\text { Males } \\
\text { Aura count per } \\
\text { person }\end{array}$ & Pre-Op Verbal IQ & $\begin{array}{l}\text { Lesion and Side } \\
\text { group }\end{array}$ \\
\hline $\begin{array}{l}3 \cdot 1 \\
2 \cdot 3 \\
1 \cdot 8 \\
1 \cdot 2 \\
\text { Mean Verbal IQ }\end{array}$ & $\begin{array}{c}113 \cdot 8 \\
102 \cdot 4 \\
101 \cdot 3 \\
94 \cdot 8 \\
\text { ales }=104 \cdot 7\end{array}$ & $\begin{array}{l}\text { ATR } \\
\text { MTSL } \\
\text { MTSR } \\
\text { ATL }\end{array}$ \\
\hline $\begin{array}{l}\text { Females } \\
\text { Aura count per } \\
\text { person }\end{array}$ & Pre-Op Verbal IQ & $\begin{array}{l}\text { Lesion and Side } \\
\text { group }\end{array}$ \\
\hline $\begin{array}{l}3 \cdot 0 \\
2 \cdot 4 \\
2 \cdot 3 \\
3 \cdot 6 \\
\text { Mean Verbal IQ } \\
\text { Total n = 79 } \\
\text { Mean Verbal IQ }\end{array}$ & $\begin{array}{l}108 \cdot 1 \\
101 \cdot 4 \\
101 \cdot 0 \\
87 \cdot 8 \\
\text { nales }=101 \cdot 0 \\
\cdot 3\end{array}$ & $\begin{array}{l}\text { MTSR } \\
\text { ATR } \\
\text { ATL } \\
\text { MTSL }\end{array}$ \\
\hline
\end{tabular}

only be made in consideration of the number of patients in each group, which means considering the number of auras per person.

\section{(3) Number of auras per person}

Table 2 shows the distribution of auras between the groups and the mean number of auras per person in those groups. The AT group averaged 2.4 auras per person and the MTS group 2.5; left-operated patients 2.2 and right 2.7 ; females averaged 2.7 and males 2.3 auras per person. There is a slight excess of auras in the ATR group (2.85) as compared with ATL (1.75) (Mann Whitney $\mu$ test $\mathrm{p}<0.057$ ).

By forming eight groups the " $N$ " is so reduced that statistically significant differences between them become less likely.

\section{(4) Aura and IQ}

Pre-operation Verbal IQs (VIQ) were available for 79 patients. It was observed that, for males in particular, aura count increased with the IQ of the group. Table 3 shows that this relationship does not hold for females.

Another analysis of this possible sex difference was made by examining the mean Verbal IQ of groups of

Table 4 Number of auras and VIQ

\begin{tabular}{lcc}
\hline & \multicolumn{2}{c}{ Mean Pre-Op Verbal IQ } \\
\cline { 2 - 3 } No of Auras & Males & Females \\
\hline 0 & $91 \cdot 2$ & 108.5 \\
1 & $99 \cdot 1$ & 96.2 \\
2 & $105 \cdot 3$ & 105.4 \\
3 & 107.9 & 105.5 \\
$4+$ & 116.1 & 96.8 \\
\hline
\end{tabular}

patients determined by the number of auras they reported. For males, IQ increases regularly with the number of reported auras but this does not hold true for females (table 4).

This relationship can be explored as a correlation between aura count per person and Verbal IQ. This gives a correlation of $r=0.19$ (NS) overall but that divides into $r=0.396(p<0.005)$ for males, but $r=$ -0.08 (NS) for females. Examined by side of operation, $r=0.013$ (NS) for left operations but $r=0.31$ $(p<0.04)$ for right operations. Analysed on the basis of the underlying lesion, neither correlation (AT, $r=$ 0.29 ) (MTS $r=0.09$ ) is significant, but there is a distinct suggestion that they exert a different effect. These contrary relationships between sexes and between sides reveal the danger of analysing at too coarse a level.

Since Verbal IQ is itself strongly related to age of onset of epilepsy, analysis of variance and covariance was made. They confirmed the powerful effect of age of onset of epilepsy on Verbal IQ but, controlling for age of onset, revealed significant residual effects within the eight groups suggesting that aura count varies with sex, side and lesion type. Thus the number of auras per person varies both with Verbal IQ and with side and sex effects independently of age of onset of epilepsy.

\section{(5) Level 2}

This analysis reduced the classification to three possible types of aura. Of the 79 patients who reported auras, 61 described Simple Primitive auras, 31 auras of the Special Senses, and 46, Intellectual auras (table 1). Only 37 patients reported auras in one single category, of whom 23 reported Simple Primitive auras, five auras of Special Senses and nine Intellectual auras alone.

\section{(6) Single and multiple auras}

In 42 patients there were auras of more than one category so the problem arises as to whether the associations are more typical of one or of another category. Eight new independent non-overlapping groups can be created (table 5) which allows independent analysis of these groups by summing all those with, for example, Simple Primitive aura in their aura make-up and contrasting it with the rest.

This analysis is of considerable interest. Considering the columns of table 5 starting with A, patients who experienced exclusively simple primitive aura, the figures suggest an excess of MTS (15 versus 8), the slight excess of right-sided cases, males, and an excess of IQs below 100, and an important age of onset effect. This is a confirmation of what we believe we know about the origin, nature and site of mesial temporal sclerosis. Auras of special senses B, or as BC are 
Table 5 Associations of all possible combinations of three aura groups

\begin{tabular}{|c|c|c|c|c|c|c|c|c|c|c|}
\hline & & $A$ & $\boldsymbol{B}$ & $C$ & $A B$ & $A C$ & $B C$ & $A B C$ & 0 & Total \\
\hline $\begin{array}{l}\text { (a) } \\
\text { (b) } \\
\text { (c) } \\
\text { (d) } \\
\text { (e) }\end{array}$ & $\begin{array}{l}\text { AT } \\
\text { MTS } \\
\text { Left } \\
\text { Right } \\
\text { Male } \\
\text { Female } \\
\text { VIQ }<100 \\
\text { VIQ }>100 \\
\text { (Not Tested or NK) } \\
\text { Age }<10 \\
\text { Onset }>10\end{array}$ & $\begin{array}{r}8 \\
15 \\
9 \\
14 \\
14 \\
9 \\
16 \\
6 \\
1 \\
21 \\
2\end{array}$ & $\begin{array}{l}3 \\
2 \\
2 \\
3 \\
2 \\
3 \\
1 \\
4 \\
0 \\
2 \\
3\end{array}$ & $\begin{array}{l}5 \\
4 \\
4 \\
5 \\
9 \\
0 \\
0 \\
8 \\
1 \\
4 \\
5\end{array}$ & $\begin{array}{l}1 \\
4 \\
2 \\
3 \\
2 \\
3 \\
4 \\
1 \\
0 \\
4 \\
1\end{array}$ & $\begin{array}{r}9 \\
7 \\
8 \\
8 \\
8 \\
8 \\
5 \\
9 \\
2 \\
11 \\
5\end{array}$ & $\begin{array}{l}2 \\
2 \\
2 \\
2 \\
4 \\
0 \\
1 \\
3 \\
0 \\
0 \\
4\end{array}$ & $\begin{array}{r}12 \\
5 \\
8 \\
9 \\
9 \\
8 \\
5 \\
9 \\
3 \\
6 \\
11\end{array}$ & $\begin{array}{l}7 \\
2 \\
6 \\
3 \\
6 \\
3 \\
3 \\
4 \\
2 \\
3 \\
6\end{array}$ & $\begin{array}{l}(88) \\
(88) \\
(88) \\
(88) \\
(88)\end{array}$ \\
\hline
\end{tabular}

$\mathrm{A}=$ Simple Primitive; $\mathbf{B}=$ Special Senses; $\mathbf{C}=$ Intellectual; $\mathbf{A B}=\mathbf{A}+\mathbf{B} ; \mathbf{A C} ; \mathbf{B C} ; \mathbf{A B C}$; No Aura.

Table 6 Idiosyncratic auras

\begin{tabular}{|c|c|c|}
\hline A. & $\begin{array}{l}\text { Déja vu with micropsia. Partial penile erection. Sense of } \\
\text { being enveloped by a monster. }\end{array}$ & $\begin{array}{l}\text { Objects recede as the mind goes blank. Voices say "get out of } \\
\text { my sight", "you must not be seen". }\end{array}$ \\
\hline B. & Feeling of inferiority (defenestrator). & $\begin{array}{l}\text { A word suddenly "occurs" and lasts in the mind (parasitic } \\
\text { word). A figure like myself comes from behind like a shadow. } \\
\text { There is a band playing in the distance. }\end{array}$ \\
\hline C. & $\begin{array}{l}\text { "As if someone is going to kill me". "As if my head is } \\
\text { drawing together". }\end{array}$ & $\begin{array}{l}\text { Grieg's "Morning" played "for hours". A voice shouts "stop } \\
\text { it". Mother and father appear. }\end{array}$ \\
\hline D. & $\begin{array}{l}\text { Derealisation, two lines of thought. Feelings like an } \\
\text { anaesthetic, suspended in time but time accelerates. }\end{array}$ & $\begin{array}{l}\text { Cosmic questions "why do I exist?" "Why do I have children?" } \\
\text { With smell of faeces when servants emptied latrines of } \\
\text { early childhood. } \\
\text { MTS }\end{array}$ \\
\hline
\end{tabular}

too few for analysis. Those with exclusively intellectual areas (C) are all males of VIQ above 100. The mixture of $A$ and $C$ seems to cancel their opposite effects except for an early onset of epilepsy. The combination of all these auras $A B C$ is characteristic of later onset epilepsies with AT lesions (12 versus 5).

\section{(7) Psychosis}

There was no significant difference in aura content between psychotic and non-psychotic patients.

\section{(8) Handedness}

No effects were observed.

\section{(9) Idiosyncratic aura}

Nearly a quarter of all the patients reported an aura of such complexity, so couched in terms of personal interpretation of their subjective experience, that the report defied further classification. Selected abbreviated examples are listed in table 6. It is this category of aura experience that raises crucial queries in neurophysiology and in psychiatry. No relationship was found between this type of aura and the schizophrenia-like psychosis of epilepsy.

\section{Discussion}

The sample of patients whose auras are described here were drawn from a larger group who had undergone temporal lobectomy for the relief of intractable epilepsy. The advantage is that a great deal is known about these patients and precise contrasts between patients with different lesions in the resected lobes is possible. The location of the lesion is known and no patient is included who does not have an identified lesion. The disadvantage is that the sample is drawn from a sub-set of people with temporal lobe epilepsy and hence its findings might not be widely applicable to all patients with temporal lobe epilepsy. However, it is the broad concept of "temporal lobe epilepsy" which is the weaker concept. The purpose of this study was to attempt to adduce the particular rules which govern aspects of cerebral function, injury, and repair or compensation. The precise nature of the study allows serious consideration to be given to neurophysiological and development issues which appear to govern the description of these subjective experiences. The study is repeatable prospectively and with advantages within several of the neurosurgical departments now operating on similar patients.

The issue of classification of auras also requires discussion. Jackson's ${ }^{26}$ original distinction into "crude warnings" and "elaborate mental states" had much to commend it. Auras are insubstantial, they are reports of a subjective experience given by one person to be understood by another. To elicit them from a patient who is reluctant to talk about them requires time and talent, and a belief in their importance. 
Some studies with very low aura rates might have missed these points. Theodore et al $^{27}$ for example, are cynical of déja vu but say nothing of jamais vu, or déja and jamais entendu. The more complex auras are, the more they will have been subject to systematic simplification. As insubstantial elements, they might be classified according to some a priori invented rule of thumb, in much the same way that angels were once seen as belonging to three hierarchies each consisting of three orders. Without the constraint of known internal or external points of reference, they can be reported grouped in any way that pleases. The most important factor is to produce a classification which works to some purpose.

This paper introduces the concept of aura complexity both in the sense of number of auras per person and in idiosyncratic richness of experience. Even a tripartite classification proved to require careful analysis of the eight groups to which it gave rise before it emerged that Simple Primitive Auras could be usefully distinguished from Intellectual Auras in terms of their associated characteristics. Age of onset, sex, side and nature of the lesion proved to be the most meaningful of those associated characteristics. The overall yield of the analysis is, however, modest in terms of the sorts of predictions which might be made in respect of the girl whose vignette appears in the introduction or indeed any other patient. There are five areas which deserve some comment in the light of this paper.

\section{(1) Neurology}

Aura is not a necessary component of epilepsy which arises from a lesion of the temporal lobe. Auras of taste and smell may relate reliably to the presence of temporal lobe lesions but they are relatively infrequent. Aura complexity increases with VIQ in males and this may suggest a right brain origin of the epilepsy. No particular aura seemed ominous in terms of outcome.

\section{(2) Neurophysiology}

No attempt is made in this paper to relate aura to the precise location of the lesion within the temporal lobe but there are suggestive factors. Mesial temporal sclerosis conforms in its aura profile to what is known about the formation and location of that lesion. It is associated with slightly lower IQ (especially in females) and with the vegetative, "simple primitive" phenomena which Van Buren ${ }^{28}$ found in his experiments in stimulating mesial temporal structures. Alien tissue lesions might be found in many locations other than the mesial structures, so the effect of varying location is to some extent tested, but without significant effect except through an association with verbal intelligence in men.

While it seems reasonable that simple primitive auras arise by local excitation of adjacent structures serving sensory purposes, this is an inadequate explanation of the more complex auras. Penfield ${ }^{13}$ and Mullan and Penfield ${ }^{17}$ described "experiential hallucinations" in some of his patients as a result of cortical stimulation. Finding, at times, that returing to restimulate the same cortical point, he produced the same hallucination, he seems to argue for some pointspecific topographical location of the memory for events within the temporal lobe, perhaps akin to the motor and sensory homunculi. These experiments had such a powerful and pervasive influence that the evidence deserves review here in the light of current knowledge and recent experiments. His major anale ysis of this data was undertaken with Perot in 1963. ${ }^{2}$ In fact only 53 of his 520 patients experienced "experiential hallucinations" in their spontaneous seio zures. Only $40(7.6 \%)$ reported "experiential hallus cinations" during point stimulation during tempora lobe surgery. Thus there were 29 patients with spontas neous experience alone, 24 had both spontaneous an induced hallucinations and 16 had induced hallu= cinations only. These can be examined by sex and by side, though the nature of the lesions is unknown (table 7). The figures suggest that inducing experiential hallucinations, albeit most of them of a very crude type, was not easy or commonplace. They were more difficult to induce when they were not also spontaneous. When they were induced, most were in the group of females being operated on the right, whereas they arose spontaneously most in males operated on the left. This makes it difficult to see continuity between the spontaneous and the induced phenom-

Table 7 Sex and side of lesion or stimulus (Penfield, Perot ${ }^{29}$ )

\begin{tabular}{|c|c|c|c|c|c|}
\hline & \multicolumn{2}{|c|}{ Male } & \multicolumn{2}{|c|}{ Female } & \multirow[b]{2}{*}{ Total } \\
\hline & Left & Right & Left & Right & \\
\hline $\begin{array}{l}\text { Spontaneous only } \\
\text { Spontaneous and induced } \\
\text { Induced only }\end{array}$ & $\begin{array}{r}14 \\
4 \\
4\end{array}$ & $\begin{array}{l}5 \\
7 \\
3\end{array}$ & $\begin{array}{l}6 \\
4 \\
3\end{array}$ & $\begin{array}{l}4 \\
9 \\
6\end{array}$ & $\begin{array}{l}29 \\
24 \\
16\end{array}$ \\
\hline Total & 22 & 15 & 13 & 19 & 69 \\
\hline
\end{tabular}


ena. It seems possible that a small minority of patients might have an unusual form of cerebral organisation as part of a mechanism compensating for the effects of their chronic cerebral lesion.

Halgren $e a^{30}$ in a meticulous report showed that only $7.6 \%$ of 3,495 mesial temporal stimulations gave rise to "experiential hallucinations" even including in that term phenomena recorded here as "simple primitive auras". There was no lateralisation effect, though subsequent foci were determined in 21 right and seven left temporal lobes in their 36 patients. Phenomena were evoked as readily from either temporal lobe. The most significant finding was that, of stimuli that gave rise neither to an evoked potential nor an after-discharge, only $2.4 \%$ were associated with a mental response; $5.5 \%$ of those with evoked potential alone but $36 \cdot 2 \%$ of those evoking an after-discharge and $69 \%$ of those that gave rise to bilateral afterdischarges. In all, $89 \%$ of evoked mental phenomena werre accompanied by an after-discharge or evoked potential. But this represented only $10 \%$ of those stimuli that produced after-discharge or evoked potentials. These authors say that experiential phenomena are most likely to occur when hippocampal neuronal activity is profoundly disrupted as in natural dreaming and after LSD. They find the phenomena evoked by mesial temporal stimulation idiosyncratic, variable from time to time and from stimulation to stimulation, and related to the personality of the subject. Pierre Gloor's group ${ }^{31}$ disagree. They did not find after-discharges necessary for the production of an experience. These were spontaneous or induced in 18 of their 29 patients with electrodes placed in both amygdalae. In any event, it seems that interesting experiential phenomena are uncommon, that phenomena arise more commonly when the normal function of mesial temporal structures, especially the amygdala, are disorganised, and that the matter reported may vary between individuals according to their personality make-up and their contemporary state of mind. The persistent, recurrent nature of complex aura remains unexplained but it could entail the withdrawal of an inhibition from cortical connections to the temporal lobe. Unlike patients with persistent complex auras most of the subjects in stimulation experiments do not have some powerful recurrently evoked affectively laden memory which is in any way entrained to become "conscious" at such opportunities.

However, Mahl et $a l^{32}$ and Higgins et al ${ }^{33}$ did attempt to record mental phenomena associated with brain stimulation and relate it to concurrent mental activity. The case reported by Mahl et al was a 27 year old, left-handed, woman, with onset of epilepsy around 21 years. Her aura pattern was extremely rich. The pathological changes in this woman are not recorded, but her EEG showed some bilateral temporal abnormalities with left-sided emphasis. Even this fascinating case, however, scarcely touches on psychopathologically relevant matters during the experimental interviews. A brief recent report from Rayport and Ferguson ${ }^{34}$ reveals again how the quality of socalled "evoked" emotions, produced by stimulation, are qualitatively dependant upon the concurrent background affect.

The opportunistic aspect of seizures, striking the individual at particular moments and then not again for hours or days or weeks, together with these data might suggest that particular sets of circumstances in the ambience might be needed to facilitate seizures through eliciting the aura.

\section{(3) Developmental issues}

Most patients who acquired temporal lobe epilepsy while young (aged under 10 years) experience simple primitive auras. This is partly a connection with MTS but could reflect a change in temporal lobe function between childhood and adult life. I have argued elsewhere ${ }^{24}$ that the extraordinary pattern of relationships between temporal lobe lesions and measured intelligence suggests a different pattern of cerebral organisation between the sexes. The complexity of aura experience, increasing with IQ in males, but not in females, is further suggestive of these differences in organisation between the sexes. We have a glimpse not of some absolute distinction, but a bias.

\section{(4) Psychology}

The theories of emotion of James ${ }^{35}$ and of Lange ${ }^{36}$ both suggest that emotion is experienced in relation to changes which occur in the peripheral target organ. Van Buren ${ }^{28}$ was unable to detect any gastromotor change when abdominal auras were induced. The message of auras seems to be that a range of emotional experience is capable of being elicited and experienced entirely within the brain. The lateralisation bias here is much less than that in Gupta et al. ${ }^{37}$ There is little to suggest that patients with ictal fear would be of poorer prognosis (Hermann et al ${ }^{38}$ ).

\section{(5) Psychopathology}

The astonishing poetic imagery of the complex aura seems redolent with meaning, awaiting skilled interpretation to reveal its psychopathological import. What might be important, as with dreams, is what the patient chooses to report out of an internal experience. The reports tend towards a certain "cosmic" quality which may reflect only the degree of partial unconsciousness, in a real sense the occupation of more than one world. These states seem better described by women, and by men of better verbal 
intelligence. This is likely to be marginally better in men with right brain lesions. Perhaps a sound left brain is needed to describe the right brain's folly? The finding is consistent with Jackson's view of aura as a release phenomenon. ${ }^{9}$ The occurrence and report of these cosmic events might be responsible for a certain awe in which people with epilepsy have been held. Auras at times contain complex states such as "embarrassment", ${ }^{39}$ which being autochthonous suggest that they are initiated within brain, but also suggest that quite complex states of being are capable of being "triggered" as simple anxiety might be. Penfield gave Lawrence Kubie the opportunity to spend time during the stimulation experiments under the wraps with the patients. Kubie ${ }^{40}$ accords the temporal lobe the function of imbuing memories with appropriate feeling tone. This might be the task of man's evolved rhinencephalon. Certainly there is an intense relationship between certain smells and feeling states. Kubie further argues that the temporal lobe has the task of sorting out the concrete and the symbolic meaning of words, he noted that a snake is also a "snake in the grass" as well as a "snake-like thing" such as a penis or a stomach tube! This aspect of temporal lobe dysfunction could lead to deviations due to being too concrete or too symbolic in thinking, deviations not infrequently described in patients with temporal lobe epilepsy. If it is hard to distinguish foot, from football or either from footie-footie, then hypergraphia, pedantry and paranoia may ensue. One meaning evokes powerful implications of the others, that way madness lies, and genius of course.

\section{References}

1 Auden WH. "Shorts" I. In: Mendelson E, ed. Collected Poems. London: Faber \& Faber, 1976.

2 Ounsted C. Some aspects of seizure disorders. In: Hull D, Gairdner D, eds. Recent Advances in Paediatrics. London: Churchill, 1971.

3 Galen. Opera Omnia. Kuhn CG, ed, Leipzig, 1821.

4 Bernard of Gordon. Cited in: Temkin O, The Falling Sickness (2nd Edition Revised). Baltimore: Johns Hopkins Press, 1971.

5 Gastaut H, Toga M, Roger J, Gibson WC. A correlation of clinical, electroencephalographic and anatomical findings in nine autopsied cases of "Temporal Lobe Epilepsy". Epilepsia 1959;1:56-85.

6 Griesinger W. Mental Pathology and Therapeutics. Translated by $\mathbf{C}$ Lockhart Robertson and $\mathrm{J}$ Rutherford. London: New Sydenham Society, 1867.

7 Cheyne J. Epilepsy. In: Forbes J, et al, eds. The Cyclopaedia of Practical Medicine, revised by Robley Dunglison, Vol 2, pp 75-91. Philadelphia: Lea and Blanchard, 1845.

8 Taylor DC, Marsh SM. Huglings Jackson's Dr Z: the paradigm of temporal lobe epilepsy revealed. J Neurol Neurosurg Psychiatry 1980;43:758-67.
9 Jackson HJ. On a particular variety of epilepsy ("Intellectual Aura"), one case with symptoms of organic brain disease. Brain 1880;11:179-207.

10 Butler S. Life and Habit. Reissued edition, 1981. London: Wildwood House Ltd.

11 Lennox WG, Cobb S. Aura in epilepsy: a statistical review of 1,359 cases. Arch Neurol Psychiatry 1933;30:374-87.

12 Commission on classification and terminology of the International League against epilepsy. Proposal for revised clinical electroencaphalographic classification of epileptic seizures. Epilepsia 1981;22:489-501.

13 Penfield W. The cerebral cortex in man. Arch Neurol Psychiatry 1938;40:417-42.

14 Hill D, Mitchell W. Epileptic anamnesis. Folia Psychiatr Neurol et Neurocht Neerl 1953;56:718-25.

15 Horowitz MH, Adams JE, Rutkin BB. Visual imagery on brain stimulation. Arch Gen Psychiatry 1968; 19:469-86.

16 Hendrick I. Psychoanalytic observations on the aurae of two cases with convulsions. Psychosom Med 1940; 2:43-52.

17 Mullan S, Penfield W. Illusions of comparative interpretation and emotion. Arch Neurol Psychiatry 1959; 81:269-84.

18 Taylor DC. Epileptic experience, schizophrenia and the temporal lobe. McLean Hospital Journal, Special Issue 1977:22-37.

19 Taylor DC, Falconer MA. Clinical, socio-economic and psychological changes after temporal lobectomy for epilepsy. Br J Psychiatry 1968;114:1247-61.

20 Taylor DC. Mental state and temporal lobe epilepsy. Epilepsia 1972;13:727-65.

21 Taylor DC. Aggression and epilepsy. J Psychosom Res 1969;13:229-36.

22 Taylor DC. Sexual behaviour and temporal lobe epi-ê lepsy. Arch Neurol 1969;21:510-6.

23 Falconer MA, Taylor DC. Surgical treatment of drugresistant epilepsy due to mesial temporal sclerosis. Arch Neurol 1968;19:353-61.

24 Taylor DC. Developmental stratagems organizing intellectual skills: evidence from studies of temporal lobectomy for epilepsy. In: Knights RM, Bakker DJ, eds. The Neuropsychology of Learning Disorders. London: University Park Press, 1976.

25 Taylor DC. Factors influencing the occurrence of schizophrenia-like psychosis in patients with temporal lobe epilepsy. Psychol Med 1975;5:249-54.

26 Jackson JH. On right or left-sided spasm at the onset of epileptic paroxysms, and on crude sensation warnings and elaborate mental states. Brain 1881;3:192-306.

27 Theodore WH, Porter RJ, Penry JK. Complex partial seizures: clinical characteristics and differential diagnosis. Neurology 1983;33:1115-21.

28 Van Buren JM. The abdominal aura: a study of abdominal sensations occurring in epilepsy and produced by depth stimulation. Electroencephalogr Clin Neurophysiol 1963;15:1-19.

29 Penfield W, Perot $P$. The brain's record of auditory and visual experience-a final summary and discussion. Brain 1963;86:595-696.

30 Halgren E, Walter RD, Cherlow DG, Crandall PH. 
Mental phenomena evoked by electrical stimulation of the human hippocampal formulation and amygdala. Brain 1978;101:83-117.

31 Gloor P, Olivier A, Quesney LF, Andermann F, Horowitz $\mathrm{S}$. The role of the limbic system in experiential phenomena of temporal lobe epilepsy. Ann Neurol 1982;12:129-44.

32 Mahl GF, Rothenberg A, Delgado JMR, Hamlin H. Psychological response in the human to intracerebral electrical stimulation. Psychosom Med 1964;24: 337-68.

33 Higgins JW, Mahl GF, Delgado JMR, Hamlin H. Behavioral changes during intracerebral electrical stimulation. Arch Neurol Psychiatry 1956;76:399-419.

34 Rayport M, Ferguson SM. Qualitative modification of sensory responses to amygdaloid stimulation in man by interview content and context. Electrocencephalogr
Clin Neurophysiol 1974;34:714.

35 James W. The Principles of Psychology. New York: Holt, 1890.

36 Lange CG. Om Sindsbevoegelser. 1885.

37 Gupta AK, Jeavons PM, Hughes RC, Covanis A. Aura in temporal lobe epilepsy: clinical and electroencephalographic correlation. J Neurol Neurosurg Psychiatry 1983;46:1079-83.

38 Hermann BP, Dikmen S, Schwartz MS, Karnes WE. Interictal psychopathology in patients with ictal fear: a quantitative investigation. Neurology 1982;32:7-11.

39 Devinsky O, Hafler DA, Victor J. Embarrassment as the aura of a complex partial seizure. Neurology 1982;32:1284-5.

40 Kubie LS. Some implications for psychoanalysis of modern concepts of the organization of the brain. Psychoanal $Q$ 1953;22:21-68. 